To the Editors:

\title{
Scalp metastasis in a patient with phaeochromocytoma
}

\author{
Ceylon Medical Journal 2011; 56: 180-181
}

Phaeochromocytomas are catecholamine secreting tumours arising from chromaffin cells of the adrenal medulla [1]. $10 \%$ of the tumours are bilateral and $10 \%$ are malignant. Malignant tumours most commonly metastasise to lungs, bone, liver or lymph nodes or may recur locally [1]. Surgical resection is the treatment of choice followed by adjuvant combined chemotherapy [1]. Five year survival rate for malignant phaeochromocytoma is $23-44 \%$ compared with $97 \%$ in benign phaeochromocytoma.

Non hormone secreting phaeochromocytomas are uncommon and the development of pulsatile scalp metastases have not been reported previously. Clinically aggressive behaviour can be predicted by the phaeochromocytoma of the adrenal gland scaled score (PASS) [1]

A 41-year old male with left loin pain had CT evidence of a mixed echogenic left renal mass without local invasion or distant metastases (Figure 1). A radical nephrectomy was performed. Histology revealed a chromogranin positive phaeochromocytoma without capsular or vascular invasion (Figure 2). PASS was 8 (Scale 1-20). Urinary VMA was negative. After 9 months patient presented with a pulsatile scalp lump (Figure 3). Investigations showed multiple metastases in the liver, skull and ribs. Treatment was continued with combined chemotherapy.

Diagnosis of phaeochromocytoma is suspected by raised urinary catecholamines and its metabolites (metanephrins rather than vanillyl mandelic acid) or raised resting plasma catecholamines and plasma chromogranin A. Clonidine suppression and glucagons stimulation tests are done only in specialised centres. CT scans and MRI scans will localise the tumour. Isotope scanning with metaiodobenzylguanidine (mIBG) express $90 \%$ success $[2,3]$.

Although the present case represents a clinically non hormone secreting phaeochromocytoma without blood pressure fluctuations, a hormone secreting tumour 


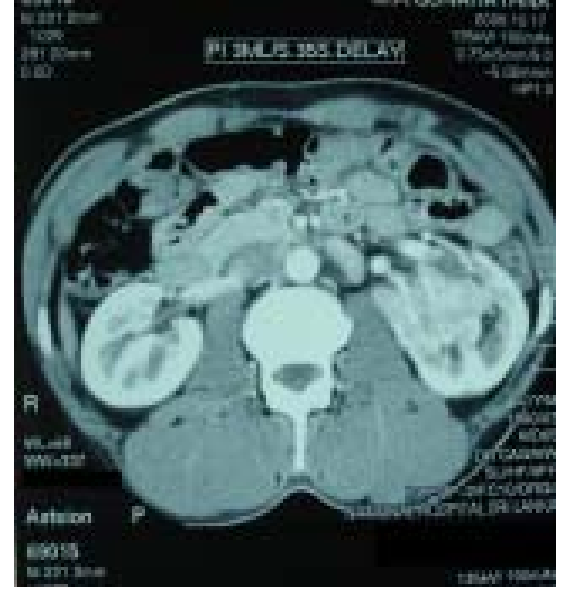

Figure 1. CT abdomen showing upper polar mass in left kidney.

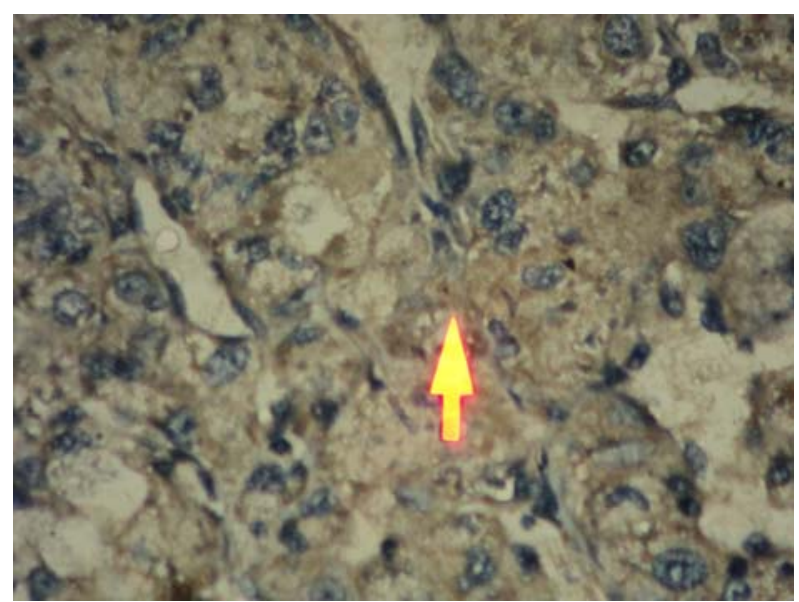

Figure 2. Brown Chromogranin reaction in cytoplasm.

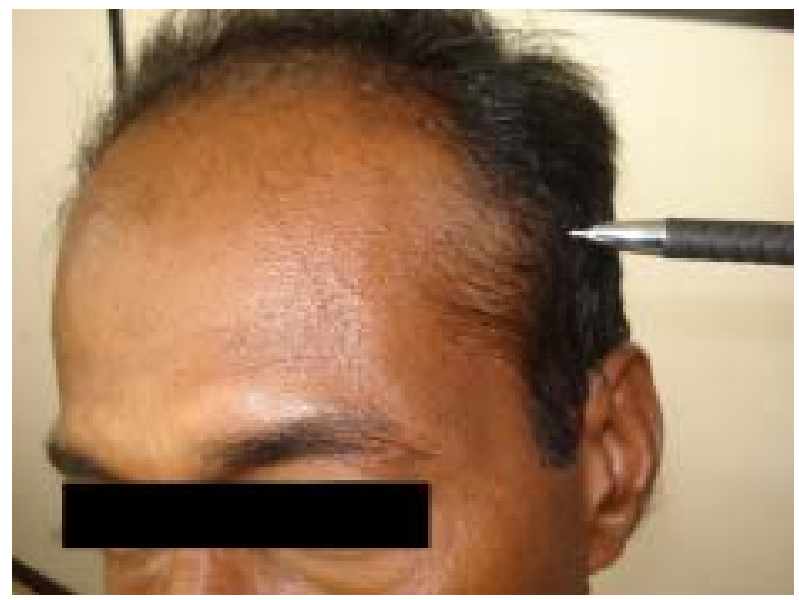

Figure 3. Pulsatile scalp lump. neutralised by conversion of catecholamines into metabolically inactive metanephrins by catecholamine methyl transferases within the tumour is a possibility [4].

In 2004 WHO defined malignant phaeochromocytoma by the presence of metastases because extensive local invasion is a poor predictor of metastasis and some tumours that metastasise show no apparent local invasion showing that the two types of aggressive behaviour have different biological basis [5].

PASS is weighted for specific histological features [1] (total score of 20). This separates tumours with a potential for biologically aggressive behaviour (PASS = or $>4$ ) from tumours that behave in a benign fashion $(\mathrm{PASS}<4)[1]$. The present case had a PASS of 8 indicating aggressive behaviour and was closely followed up. Development of previously unreported scalp metastases along with other metastasis at 9 months of follow up confirmed the accuracy of PAS Score. This also emphasizes the need for adjuvant chemotherapy in high PASS patients.

\section{References}

1. Thompson, Lester DR. Pheochromocytoma of the Adrenal Gland Scaled Score (PASS) to separate benign from malignant neoplasm: a clinicopathologic and immunophenotypic study of 100 cases. American Journal of Surgical Pathology 2002; 26: $551-66$

2. Howlett TA. Endocrine disease. In: Kumar P, Clark M, eds. Clinical Medicine. 6th Edition. Elsevier Saunders. 2005; 1098-9.

3. Maurea S, Klain M, Mainolfi C, et al. The diagnostic role of radionuclide imaging in evaluation of patients with nonhypersecreting adrenal masses. The Journal of Nuclear Medicine 2001; 42: 884-92.

4. Unger N, Pitt C, Schmidt IL, et al. Diagnostic value of various biochemical parameters for the diagnosis of phaeochromocytoma in patients with adrenal mass. European Journal of Endocrinology 2006; 154: 409-17.

5. Tischler AS. Pheochromocytoma: time to stamp out malignancy? Endocrine Pathology 2008; 19: 207-8.

\section{P A S H Gunawardhana ${ }^{1}$, L N Seneviratne ${ }^{1}$, N D Perera ${ }^{1}$}

${ }^{1}$ Department of Urology and Renal Transplantation, National Hospital of Sri Lanka.

Correspondence: PASHG, e-mail: <pashg1970@yahoo.com>. Received 18 October 2010 and revised version accepted 6 April 2011. Competing interests: none declared. 